\title{
Article \\ Size Effect on the Acoustic Emission Behavior of Textile-Reinforced Cement Composites
}

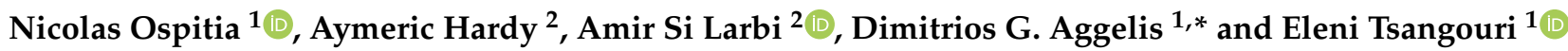 \\ 1 Department Mechanics of Materials \& Constructions (MeMC), Vrije Universiteit Brussel (VUB), Pleinlaan 2, \\ 1050 Brussels, Belgium; Nicolas.Ospitia.Patino@vub.be (N.O.); Eleni.Tsangouri@vub.be (E.T.) \\ 2 Laboratoire de Tribologie et de Dynamique des Systèmes (LTDS), Université de Lyon, Ecole Nationale \\ d'Ingénieurs de Saint-Etienne (ENISE), 58 Rue Jean Parot, 42000 Saint-Etienne, France; \\ aymeric.hardy@enise.fr (A.H.); amir.si-larbi@enise.fr (A.S.L.) \\ * Correspondence: Dimitrios.Aggelis@vub.be
}

check for updates

Citation: Ospitia, N.; Hardy, A.; Si Larbi, A.; Aggelis, D.G.; Tsangouri, E. Size Effect on the Acoustic Emission Behavior of Textile-Reinforced

Cement Composites. Appl. Sci. 2021, 11,5425. https://doi.org/10.3390/ app11125425

Academic Editor: Stefano Invernizzi

Received: 29 April 2021

Accepted: 8 June 2021

Published: 10 June 2021

Publisher's Note: MDPI stays neutral with regard to jurisdictional claims in published maps and institutional affiliations.

Copyright: (c) 2021 by the authors. Licensee MDPI, Basel, Switzerland. This article is an open access article distributed under the terms and conditions of the Creative Commons Attribution (CC BY) license (https:/ / creativecommons.org/licenses/by/ $4.0 /)$.

\begin{abstract}
Acoustic emission (AE) is applied for the structural health evaluation of materials. It commonly uses piezoelectric sensors to detect elastic waves coming from energy releases within the material. Concerning cementitious composites as well as polymers, AE parameters have proven their potential to not only detect the existence of a defect, its location and the fracture mode, but also the developing strain field even before visible damage evolves. However, the wave propagation distance, wave dispersion due to plate geometry, heterogeneity and reflections result in attenuation and distortion of the AE waveforms. These factors render the interpretation more complex, especially for large samples. In this study, the effect of wave propagation on plain glass textile-reinforced cement (TRC) plates is investigated. Then, curved plates with different width are mechanically loaded for bending with concurrent AE monitoring. The aim is to evaluate to what extent the plate dimensions and propagation distance influence the original AE characteristics corresponding to a certain fracture mechanism.
\end{abstract}

Keywords: waveform; bending; textile-reinforced cement; frequency; rise time; propagation distance; matrix crack

\section{Introduction}

Acoustic emission (AE) has successfully been used to monitor the failure process of composite media for a long time. It utilizes piezoelectric sensors to monitor the elastic waves emitted by irreversible processes like cracking and the general failure process in materials. Advancements in electronics and its affordable and non-hazardous nature, combined with its sensitivity, make it a very encouraging type of technology for damage assessment. The detection of active cracking and information on the fracture mode, something very essential for composites, as well as source localization have been extensively utilized [1-5]. It has been recently demonstrated that acoustic emission is sensitive to the applied stress field long before damage is inflicted to the polymer and cementitious composites [6-8]. The relative motion of the cracked sides depends on the fracture mode introducing different elastic waves, depending on the stress field, causing the displacement. In general, displacements due to shear stresses show lower frequencies and longer waveforms than tensile events $[2,9,10]$ (see Figure 1). Among other parameters, the frequency content is evaluated by the "average frequency" (AF), which is the number of threshold crossings of the waveform over its duration. In addition, another important shape parameter connected to the propagating wave modes and the type of excitation is the time delay between the first threshold crossing and the maximum peak of the waveform, called the "rise time" (RT). 


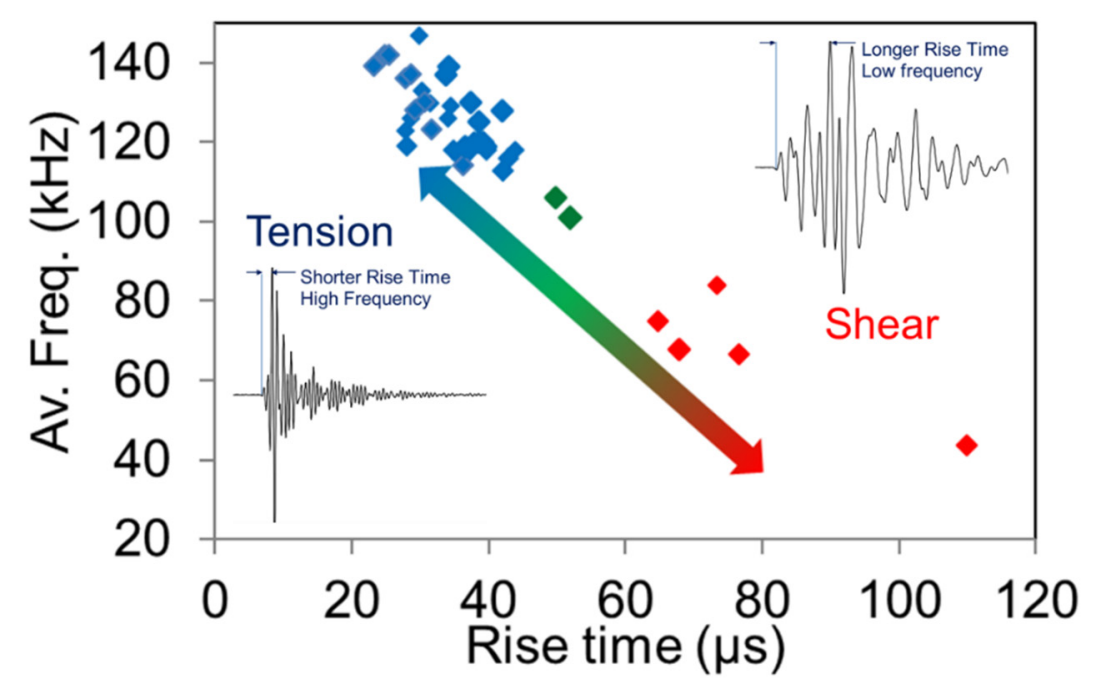

Figure 1. Average frequency-rise time plot from bending tests on TRC beams, taken from [7].

While the effectiveness of the technique has been demonstrated at a laboratory scale, and AE is extremely useful in material-oriented studies, the full potential has not been realized at a larger service scale. The reasons for this include larger propagation distances and thus higher attenuation, more possible sources of external noise and more severe signal distortion due reflections, scattering and dispersion. Therefore, away from the laboratory, the AE is mainly limited to crack detection and localization [11-14], while the sensitivity to the fracture mode and stress field are in their infancy.

The aforementioned issue of the large propagation distance has been demonstrated in bulk [15] as well as plate structures [16-19]. Studies occupying different propagation distances in thin plates have shown that due to plate wave dispersion, the elastic signals continuously undergo a waveform shape change. This is mainly because different frequency components propagate with different velocities, something that is also demonstrated herein for the specific material of interest (cementitious composite for construction). In addition, the main focus comes from an issue not sufficiently investigated in the literature. This is the lateral dimension of the plate. Practically speaking, this is the difference in the acquired $\mathrm{AE}$, when varying the width of the plate without altering the nominal propagation distance between the damage source and sensor and the fracture mechanism (see Figure 2). As the width of the plate is small, the geometry is closer to a beam, and the wave propagation is essentially one-dimensional, leading to strong waveguide behavior (Figure 2a). For larger widths though, the propagation opens in a circular wavefront, the energy is spread to larger area, and the wave travels a longer distance until it is possibly reflected by the edges (see Figure 2c), while Figure $2 b$ shows an intermediate situation.

The influence of the width on wave propagation has been studied in straight metal plates [20,21] and only recently in structural composites [22]. In general, it was found that the recorded waveforms in beams showed higher frequency contents and amplitudes than in the plates. The reason was attributed to edge reflections, which are dominant for small specimens and distort the frequency content but weaken in large dimensions. An equivalent interpretation from another point of view was given through the essentially onedimensional propagation in the beam, which resembled the propagation in a waveguide, avoiding the spreading of the wavefront. This is the first time that the effect of the plate width is studied in curved composite elements. The specific material is TRC, a cementitious matrix reinforced by chopped, randomly oriented glass fibers. Details on the material and experimental procedure follow in the next section. 

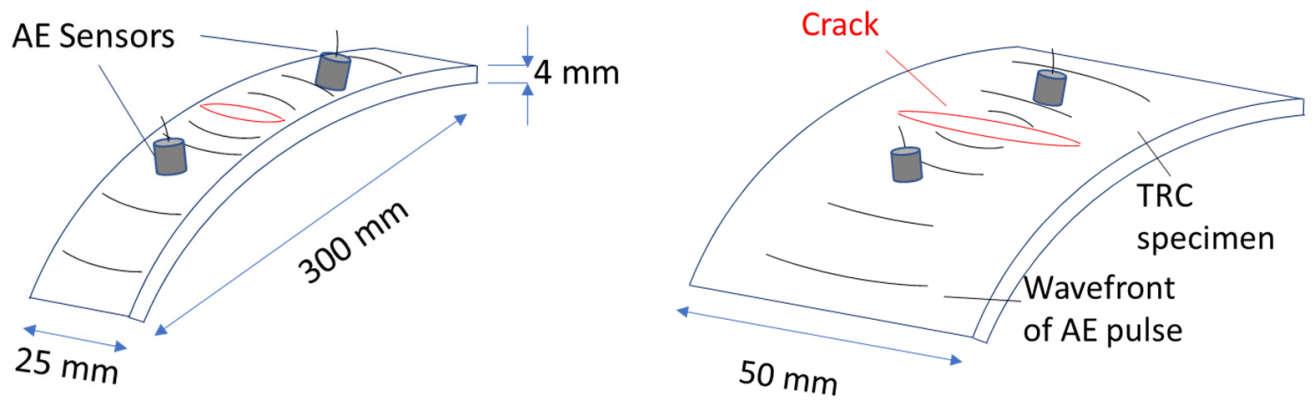

(a)

(b)

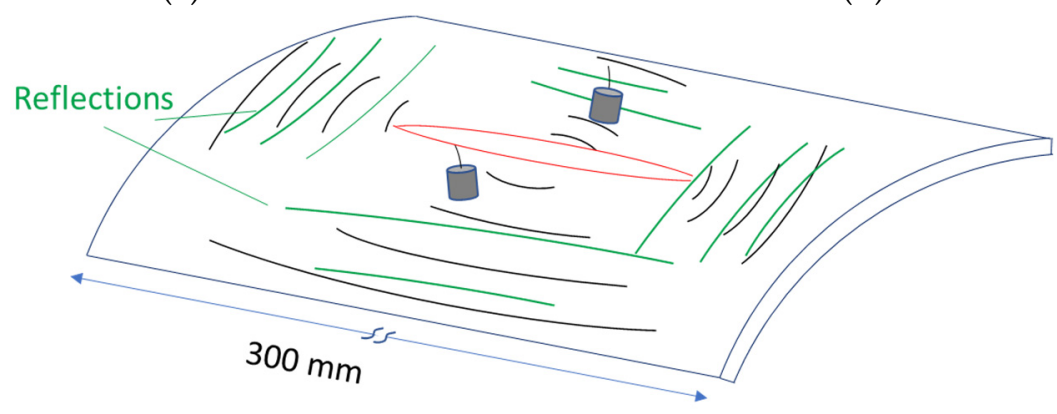

(c)

Figure 2. Schematic representation of AE in curved plates with different widths. Corresponding to (a) a beam of $25 \mathrm{~mm}$ width (b) a beam of $50 \mathrm{~mm}$ width, (c) plate with $300 \mathrm{~mm}$ width.

\section{Experimental Details}

Three series of four samples each were tested in a lab under three-point bending. The composite consisted of a wollastonite-based powder matrix (IPC, $\mathrm{CaSiO}_{3}$ ) mixed with a $1 \% v f$ ALESTA HR polymer agent. Thin plates were cast with the hand lay-up method by impregnating 8 layers of randomly chopped glass fiber textile mats reaching a $20 \%$ volume fraction. The plates were cast into curved molds with both the length and width fixed at $300 \mathrm{~mm}$. The height was set at $150 \mathrm{~mm}$. The $4-\mathrm{mm}$ thick plates were cured at $60{ }^{\circ} \mathrm{C}$ for $24 \mathrm{~h}$ after casting. Then, the plates were cut into samples with varying widths of 25,50 and $300 \mathrm{~mm}$. After curing at room temperature for at least $24 \mathrm{~h}$ more, the samples were tested for bending until failure using an INSTRON testing bench with a load cell capacity up to $10 \mathrm{kN}$. The test was displacement controlled, and the point of load application in the middle of the beam was moving downward with a constant speed of $0.02 \mathrm{~mm} / \mathrm{s}$. This relatively low speed was applied in order to allow the slow development of fractures, avoiding interactions between different fracture sources as much as possible. The sample was confined along both sides (Figure 3a,b).

Four AE sensors were mounted at the top side of the sample with the use of tape in the configuration illustrated in Figure 3c. A thin layer of vacuum grease between the sensors and the specimens was applied for acoustic coupling. Resonant $(150 \mathrm{kHz}) \mathrm{R} 15$ sensors, provided by Mistras Group, were used. Three of the AE sensors were positioned at equal distances of $60 \mathrm{~mm}$ at one side, while the fourth one was placed at the opposite side of the sample, thus fully covering the fractured zone. The received signals were preamplified by $40 \mathrm{~dB}$, while the low noise environment enabled the application of a quite low and sensitive threshold of $35 \mathrm{~dB}$. The sampling rate was $2 \mathrm{MHz}$, while the acquisition system was a Micro-II digital AE system from Mistras Group. The signal "timing" parameters used to separate successive signals and measure their parameters were as follows: hit definition time $=200 \mu \mathrm{s}$, peak definition time $=100 \mu \mathrm{s}$, maximum hit duration $=1 \mathrm{~ms}$ and hit lock out time $=800 \mu \mathrm{s}$. These settings may have influenced the absolute value of the measured parameters and were compatible with the manufacturers' recommendations and our own experience. 


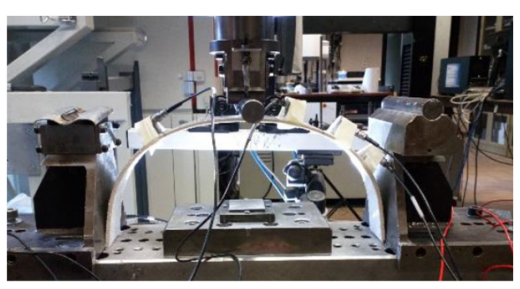

(a)

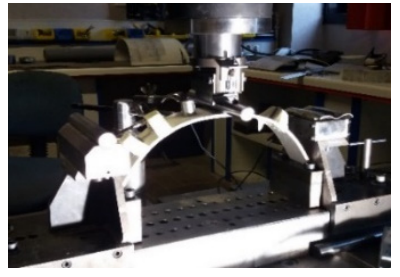

(b)

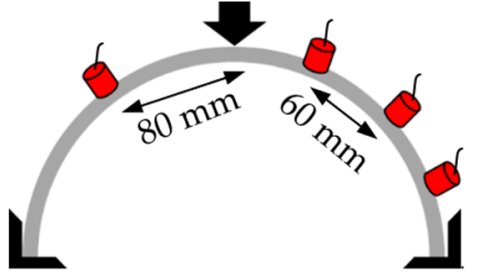

(c)

Figure 3. (a,b) Bending set-up. (c) AE sensor positions.

\section{Results}

\subsection{Effect of Propagation Distance}

To set the stage and illustrate the strongly dispersive nature of wave propagation in the specific composite, first, an example taken from a straight TRC plate is shown below. The manufacturing of the plates was similar to the curved elements but took place in a straight mold. More details can be found in [22]. Elastic wave tests were conducted with the two resonant $\mathrm{AE}$ transducers fixed on the surface of the plates at distances of $100 \mathrm{~mm}$ and $200 \mathrm{~mm}$ from the excitation (Figure 4).

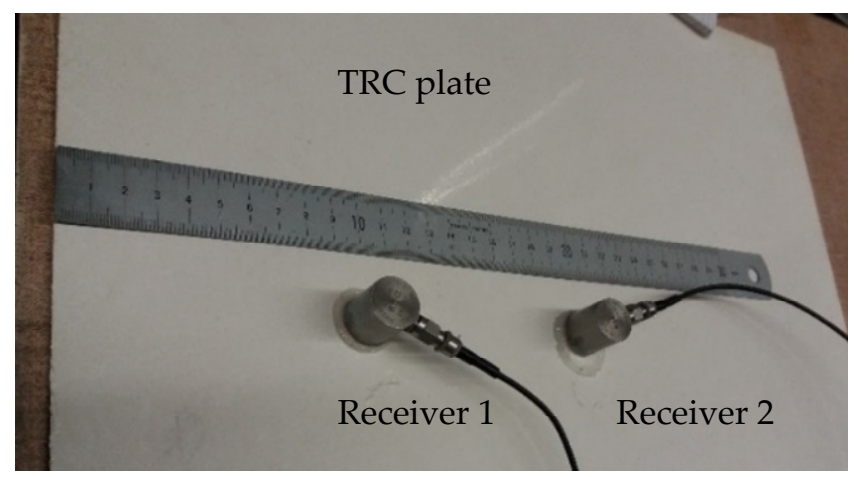

Figure 4. TRC plate with AE sensors at a distance of $100 \mathrm{~mm}$.

The excitation was conducted by a pencil-lead break, which is similar to the HsuNielsen source method [2]. It was applied on the top surface (out-of-plane) and on the edge (in-plane) to test the influence of the source's orientation, and the typical waveforms are depicted in Figure 5a,b, respectively. In both cases, the waveforms collected by the first and second receivers differed substantially even after simple visual observation.

The maximum amplitude at the second sensor decreased by approximately a factor of three or more. This was the result of the combined effect of all attenuation mechanisms (beam spreading, damping and scattering). In addition, plate wave dispersion contributed in an indirect way by spreading the wave energy over time, thus lowering the maximum amplitude. Apart from the amplitude, the shape of the waveforms would seriously change if we treated them from the viewpoint of AE. Indicatively, for the case of out-of-plane excitation, the rise time (RT) measured at $200 \mathrm{~mm}$ became almost 4 times longer than the RT at $100 \mathrm{~mm}$ due to the aforementioned dispersion and spreading in the time domain (Figure 5a). For in-plane excitation, the spreading was even stronger, with the RT increasing more than seven times for the same extra distance (from $32 \mu \mathrm{s}$ to $240 \mu \mathrm{s}$; see Figure $5 \mathrm{~b}$ ). Therefore, it is clear that the propagation distance strongly impacted the acquired waveform and, consequently, all the AE parameters. This is highlighted since, as will also be discussed later, it complicates the characterization of the fracture mode currently being attempted by analysis of the AE parameters $[2,5,7,8,11]$. 


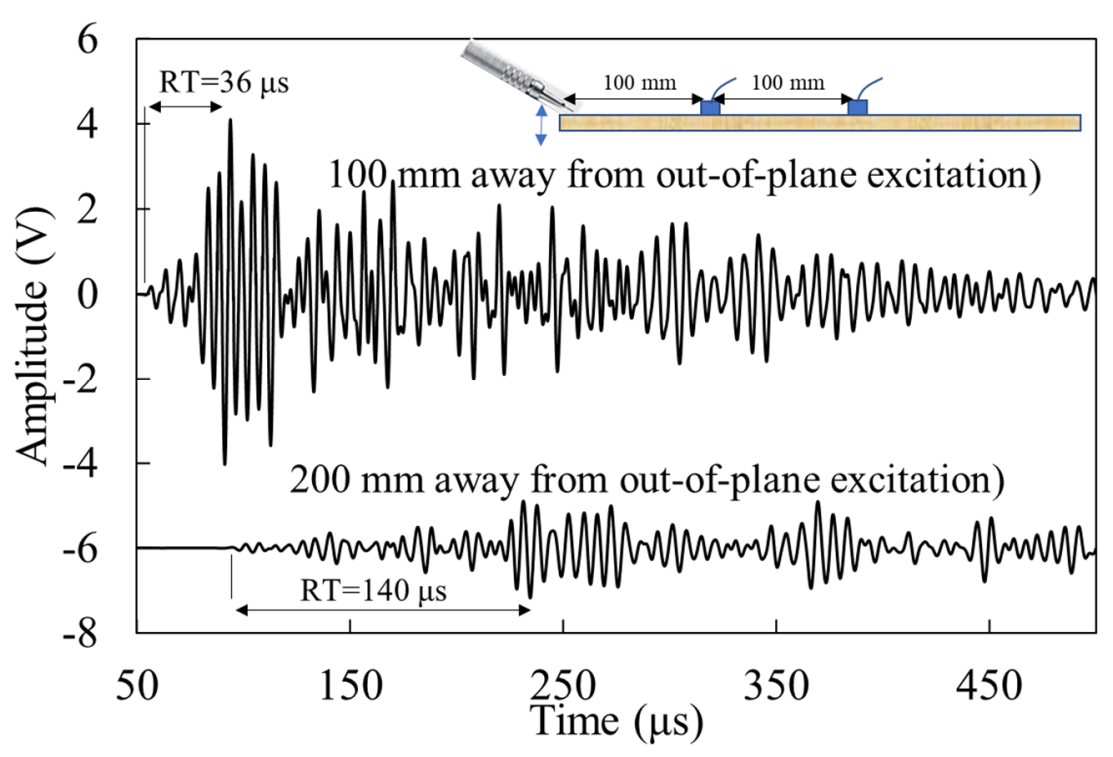

(a)

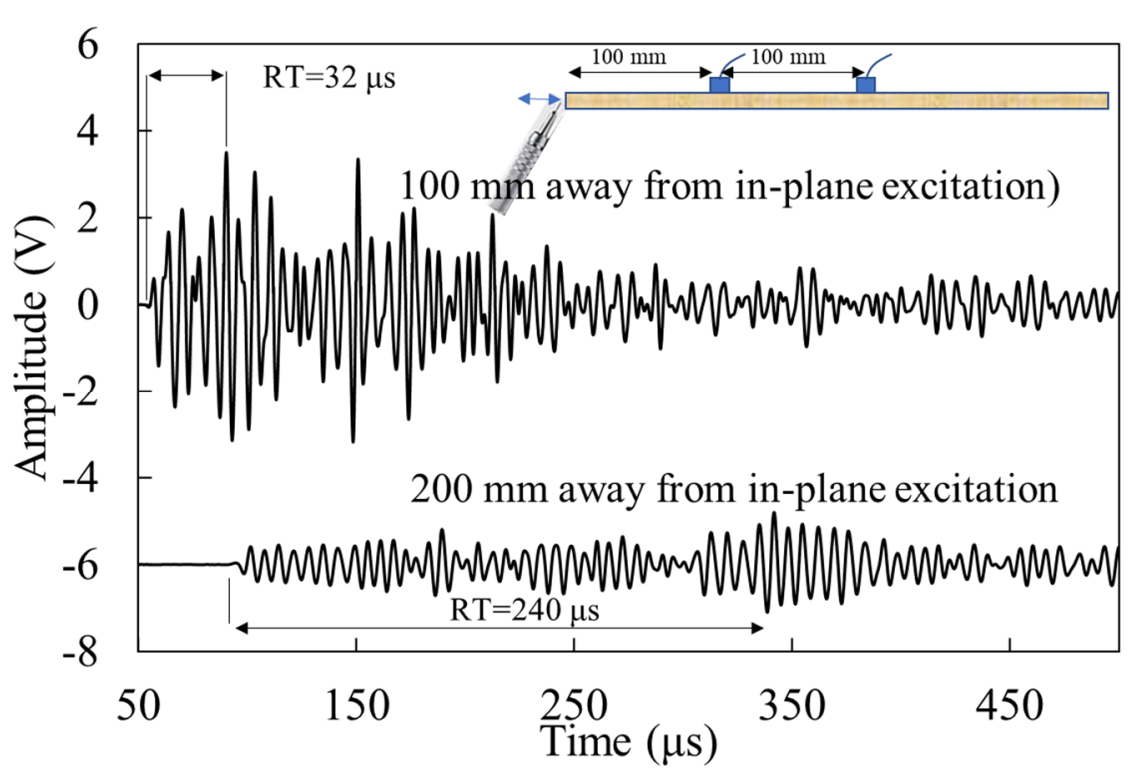

(b)

Figure 5. Waveforms from sensors at different distances from pencil lead excitation on the TRC plate: (a) out-of-plane excitation and (b) in-plane excitation. The arrow in front of the plate denotes the direction of the excitation. The amplitude values of the second sensor are shifted downward for clarity.

\subsection{Effect of the Width of the Curved Elements on AE Behavior}

The analysis started with the beam with the smallest width in order to set the basic behavior and explanation relative to the fracture of the TRC before moving to the comparisons with the plate specimen.

While the load was low, the AE was scarce. This corresponded to the elastic regime, where limited cracking was initiated. As the load increased, cracking became more frequent, and the AE rate increased, as can be seen in Figure 6a. Later on and before the final collapse, the cracking was continuous, as can be seen by the local fluctuations of the load curve, while at the end, the cumulative AE exhibited an almost vertical increase. At the same time, $\mathrm{AE}$ parameters like the rise time showed an increase with each successive stage (Figure $6 \mathrm{~b}$ ); before approximately $10 \mathrm{~min}$, it was limited to $40 \mu \mathrm{s}$, and later at approximately $12.5 \mathrm{~min}$, 
it reached $100 \mu$ s, while at the final load drop and the macroscopic collapse, it expanded to values up to $200 \mu \mathrm{s}$ or higher, as is shown in Figure $6 \mathrm{~b}$. This increase in the values of the RT was interpreted as the shift occurred from matrix cracks to delaminations and fiber pull-out as the specimen was led to final failure $[5,6]$. It must be noted here that theoretically, it is also possible that several sources were acting simultaneously or in an overlapping manner at the moments of high intensity fracturing phenomena at the end of loading. This could impact the recorded waveforms, increasing the RT and duration characteristics. Although this cannot be excluded, the pencil-lead break excitations discussed in Figure 5 show that, depending on the conditions, even a single source can be recorded with a high RT (e.g., in-plane excitation recorded at $200 \mathrm{~mm}$ distance depicted in Figure 5b), showing that these differences were connected to the actual mechanism and propagation conditions and not necessarily to the overlapping of different waveforms.

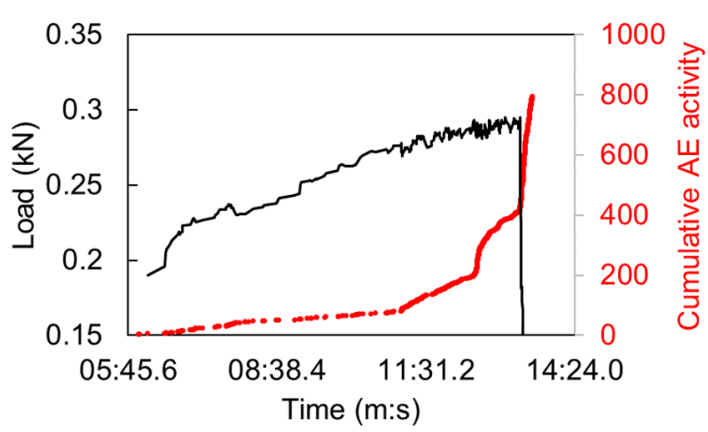

(a)

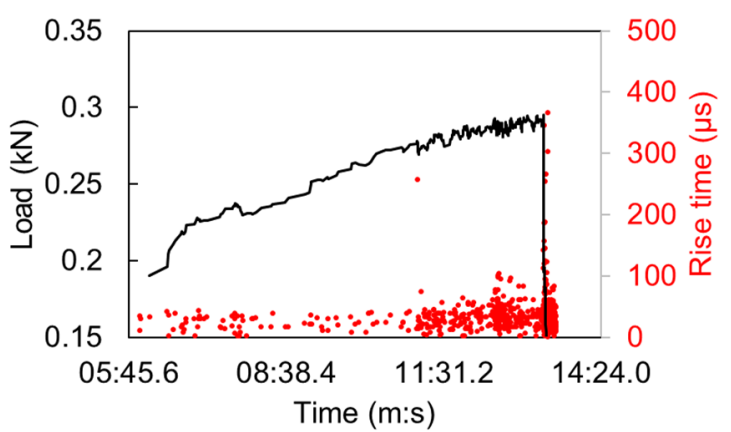

(b)

Figure 6. Load history with (a) cumulative hits and (b) rise times from a curved TRC beam $25 \mathrm{~mm}$ wide.

The corresponding results for the plate are shown in Figure 7a. A similar observation about the increase of the AE rate can be made, while it is evident that at the transient load drops (marked by arrows in Figure 7a), which indicate cracking events, the AE exhibited vertical increases. Usually, these large cracking events are also escorted by delaminations and fiber pull-out events, something responsible for the higher values of the RT that are evident at those moments (see Figure 7b). In Figure 7b, it also becomes obvious that the RT values were expanding to $100 \mu$ s from the start of the experiment, certainly higher than the $40 \mu \mathrm{s}$ limit for the beam. This is already an indication that the matrix cracks occurring at a low load corresponded to different AE signatures in beams and plates of the same material.

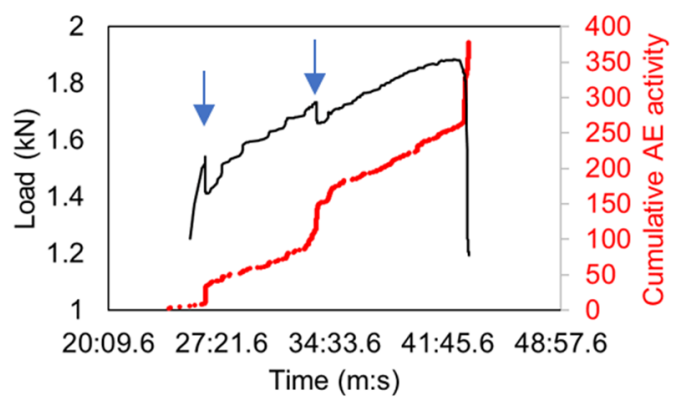

(a)

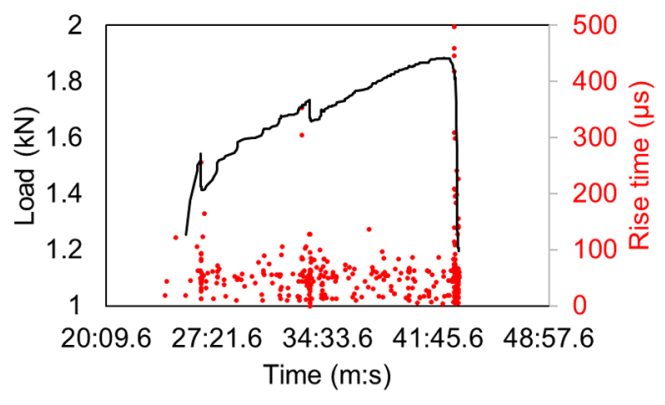

(b)

Figure 7. Load history with (a) cumulative hits and (b) rise times from a curved TRC plate $300 \mathrm{~mm}$ wide.

In order to make a valid comparison, and because the time scales of the different tests were not similar, the AE activity in terms of the RT and AF was represented versus the number of hits. The initial population of hits belonged to the elastic regime, where the dominant expected expression of damage was matrix cracks. Therefore, the AE of the 
first 200 hits was reasonably attributed to cracking without much interference from other fracture modes. At the same time, the medium was relatively undamaged, allowing us to check the effect of the geometry itself without the distortion due to damage.

Figure 8a shows the sliding average of the RT for the first 200 hits for all three specimens. The plate exhibited the highest RT, while the thin beam exhibited the lowest RT curve. After 100 hits, some peaks in the RT were seen, which were attributed, as was already mentioned, to the small load drops evidenced in Figure 6. Again, the influence of the width was obvious, as the RTs measured on the specimens exhibited an increase with the specimen's width.

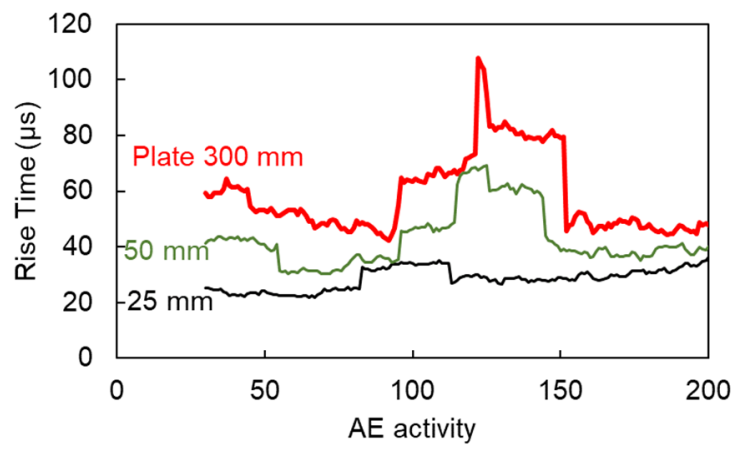

(a)

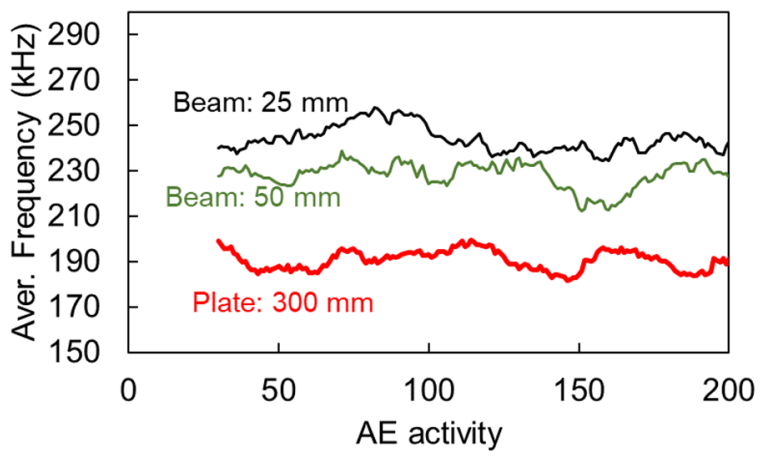

(b)

Figure 8. Sliding average of the rise time (a) and AF (b) for the first 200 hits in specimens with different widths (sliding window of 30 points).

The conclusions from the AF analysis are in the same line, showing again a systematic difference according to the specimens' width: as the width of the beam increased, the frequency content of the received waveforms due to cracking emissions decreased (Figure $8 b$ ). For the thin beam of $25 \mathrm{~mm}$, the AF line was around 240-250 kHz. For the medium beam of $50 \mathrm{~mm}$, the line was continuously lower, being between $220 \mathrm{kHz}$ and $230 \mathrm{kHz}$, while for the plate (width of $300 \mathrm{~mm}$ ), the drop was even more pronounced at approximately $190 \mathrm{kHz}$. It is seen, therefore, that despite monitoring the same basic source (cracking of cementitious matrix), the acquired $\mathrm{AE}$ parameter was strongly influenced by the geometry of the specimen (in this case, the width).

Figure 9 shows the representative waveforms collected from a $25-\mathrm{mm}$ beam and a plate $300 \mathrm{~mm}$ wide. While the indicative waveforms may have shown the expected differences (waveform of the beam peaked earlier), the obtained parameters were considered very important because, in a real structural health monitoring situation, the whole waveforms would likely not be recorded due to limitations in the recording space and the possible bandwidth of (wireless) transmission.

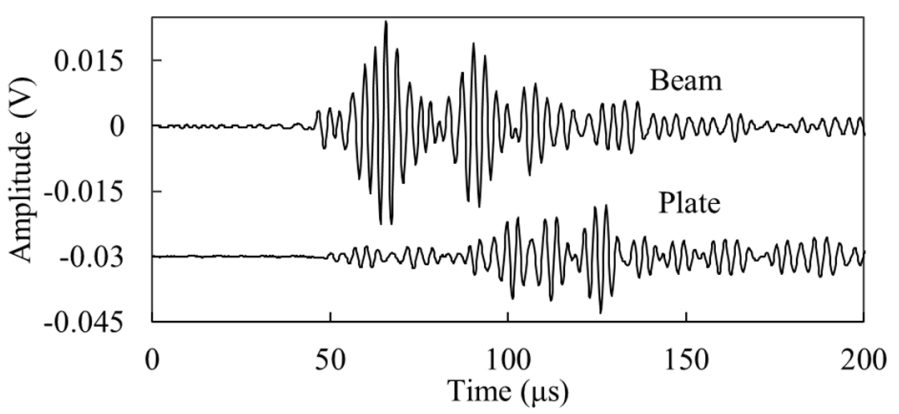

Figure 9. Representative AE waveforms during the cracking stage from a beam (width of $25 \mathrm{~mm}$ ) and a plate (width of $300 \mathrm{~mm}$ ). 


\section{Discussion}

The trends from the curved plates described herein are in good correspondence with the straight plate AE behavior of the same material under three-point bending. Figure 10 shows the sliding average of the RT for straight elements with different widths, taken from a recent study [22]. The wider specimen (width of $400 \mathrm{~mm}$ ), termed as the "plate", showed a much higher RT than the 23-mm wide beam. Gradually, with more time in the loading process, a shift to higher values is shown, as there is a reasonable shift from matrix cracks to delaminations.

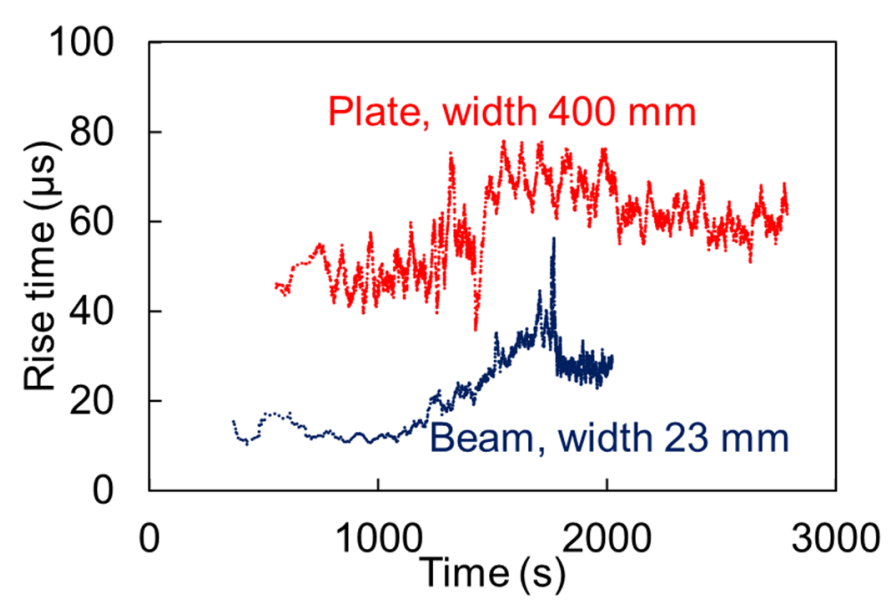

Figure 10. Sliding average of the rise time for plane TRC specimens with different widths under three-point loading.

The results from the plane specimens confirmed that the curvature of the plate in the direction of propagation was not crucial and did not significantly influence the obtained trends [23]. However, a large increase in the lateral dimension imposed large discrepancies in the received waveform, increasing the RT by two to three times both in the curved (Figure 8) and straight plates (Figure 10).

Considering the waveforms of Figure $5 \mathrm{a}$, a measure of attenuation was obtained. Extra propagation of $100 \mathrm{~mm}$ reduced the absolute amplitude by $72 \%$ (first sensor: $8.135 \mathrm{~V}$, second sensor: $2.286 \mathrm{~V}$ ). A possible side reflection needed to propagate a total of $300 \mathrm{~mm}$ (150 $\mathrm{mm}$ from the center of the plate to the edge and back), so without any other effect, it corresponded to three times the aforementioned decrease, leading to an amplitude of only $2.2 \%$ of the original. This is too small to be pinpointed in the waveform of a resonant transducer and, as such, cannot influence the measurement of the RT. Nevertheless, the calculated expected time of these negligible reflections in the plates of $300 \mathrm{~mm}$, considering a propagation velocity of approximately $3000 \mathrm{~m} / \mathrm{s}$, would be $100 \mu \mathrm{s}$. In the waveform, any corresponding contribution at that time was not clearly observed. We can conclude that for the wide specimen $(300 \mathrm{~mm})$, the energy that propagated sideways was actually lost and practically was not expected to show again in the waveforms. For the less wide specimens ( $50 \mathrm{~mm}$ and $25 \mathrm{~mm}$ ), the time of reflection arrival was less than $20 \mu \mathrm{s}$. Therefore, the contribution of the reflections was included in the main body of the waveform. Due to the duration of the main pulse, the plate wave dispersion and the sensitive, resonant nature of the transducers, isolating the reflection contributions was not a straightforward process.

To examine how the possible characterization would be influenced by the geometry, Figure 11 presents the AF vs. RT graph for the matrix cracking sources (first 100 hits) in the beam and plate. All individual points are visible, along with the average of the populations (larger symbols) and the standard deviations in the ellipses. The shift of the populations is obvious, with the plate data expanding to much higher RTs and lower frequencies, while there is no overlap for $65 \%$ of the populations, indicated by the ellipses. 


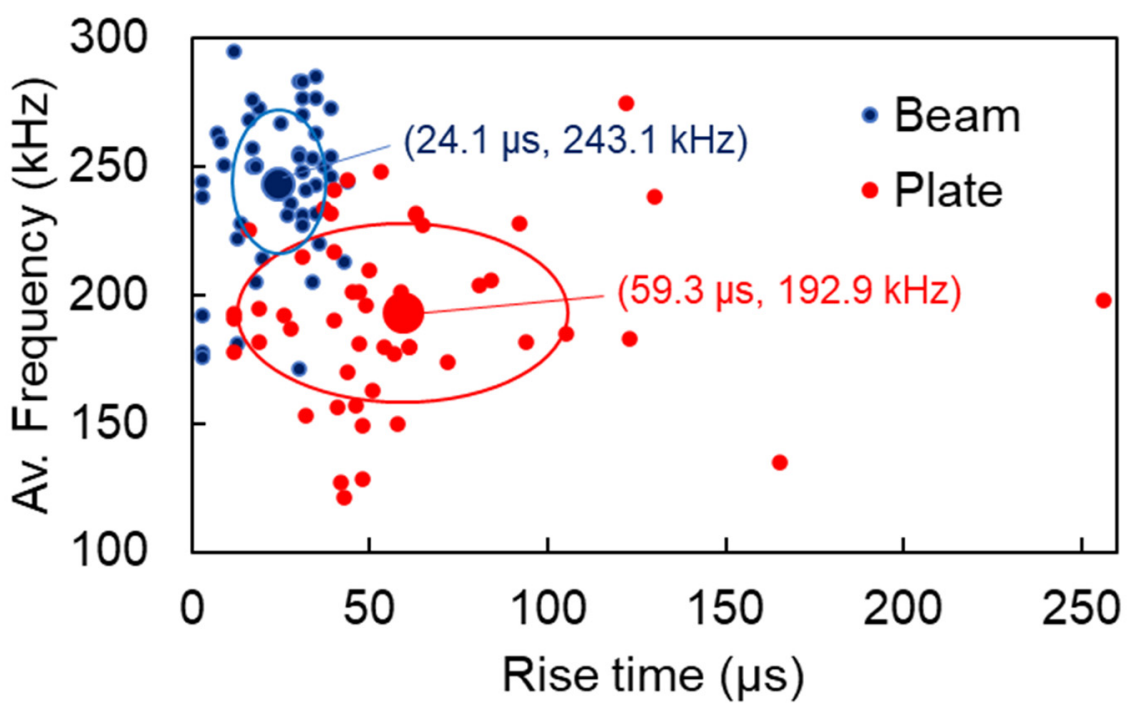

Figure 11. Average frequency vs. rise time of matrix cracking signals for a curved beam and a curved plate specimen. The large symbols denote the centers of the two populations. The axes of the ellipses are equal to the standard deviation (horizontal: rise time; vertical: average frequency).

The practical implication of this shift in AE values can be understood by considering the dominant crack classification methodology that is described in the literature and the RILEM recommendations [2]. In general, a high frequency and low RT value are connected to the tensile mode of cracking. On the other hand, a low frequency and higher RT indicates the shear type of failure. Therefore, a relative shift between values would be interpreted as a change of the dominant fracture mode. However, when we compared different type of specimens, like in the case herein, this difference in AE parameters was only the result of the different geometry (in this case, the dimension lateral to propagation, termed as the width), despite the underlying basic fracture mechanism being the same (matrix cracking). As seen in Figure 11, there was a difference of more than $50 \mathrm{kHz}$ in the average frequency value, while the RT was more than doubled for the case of the plate compared with the thin beam. By conducting calibration experiments in small-scale laboratory samples, the resulting values were not representative of the activity from more realistic samples and would cause errors in interpretation. Typically, activity in bigger samples would be misinterpreted toward shearing due to shifting to lower frequencies and longer signals.

\section{Conclusions}

Apart from active damage detection and localization, reliable interpretation is the next big challenge for $\mathrm{AE}$ in large scale. Acoustic emission is firmly connected to the elastic wave behavior of a medium. Phenomena like dispersion, attenuation and scattering, which are relevant for an ultrasonic study, are by default important for the correct evaluation of the AE signals. The present study wishes to highlight the effect of the propagation distance, as well as the dimension vertical to it, namely the plate width. It was proven that although propagation takes place in the other direction, the effect of the width is crucial, as it can strongly alter the waveform parameters. The larger the lateral dimension of the specimen, the longer the acquired AE signals being translated to higher RT and duration values. At the same time, the frequency decreases. Without prior knowledge, this substantial shift of values would be misinterpreted toward the shear nature of cracking. Therefore, it is crucial to either develop a methodology to extrapolate the expected values in larger specimens or to directly conduct the experiments in realistically sized specimens to avoid the waveguide phenomena occurring in beams. The study should continue with numerical simulations to examine the limit of the size until a strong influence is expected. 
Author Contributions: Conceptualization, D.G.A. and A.S.L.; methodology, A.H. and E.T.; experimental measurements, N.O. and A.H.; formal analysis, N.O. and A.H.; data curation, N.O., A.H., E.T.; writing—original draft preparation, D.G.A. and N.O.; writing—review and editing, A.S.L. and E.T.; supervision, D.G.A., A.S.L. and E.T.; project administration, D.G.A. and A.S.L.; funding acquisition, D.G.A., A.S.L. and E.T. All authors have read and agreed to the published version of the manuscript.

Funding: This research was funded by Fonds Wetenschappelijk Onderzoek-Vlaanderen (FWO) through grants G.0337.19N and 12J7720N.

Acknowledgments: The authors gratefully acknowledge the financial support of Fonds Wetenschappelijk Onderzoek-Vlaanderen (FWO) through grants G.0337.19N and 12J7720N.

Conflicts of Interest: The authors declare no conflict of interest.

\section{References}

1. Grosse, C.U.; Ohtsu, M. (Eds.) Acoustic Emission Testing; Springer: Berlin/Heidelberg, Germany, 2008.

2. Ohtsu, M. Recommendation of RILEM TC 212-ACD: Acoustic emission and related NDE techniques for crack detection and damage evaluation in concrete, Test method for damage qualification of reinforced concrete beams by acoustic emission. Mater. Struct. 2010, 43, 1183-1186.

3. Kundu, T. Acoustic source localization. Ultrasonics 2014, 54, 25-38. [CrossRef]

4. Kravchuk, R.; Landis, E.N. Acoustic emission-based classification of energy dissipation mechanisms during fracture of fiberreinforced ultra-high-performance concrete. Constr. Build. Mater. 2018, 176, 531-538. [CrossRef]

5. Godin, N.; Reynaud, P.; Fantozzi, G. Challenges and limitations in the identification of acoustic emission signature of damage mechanisms in composites materials. Appl. Sci. 2018, 8, 1267. [CrossRef]

6. Kalteremidou, K.-A.; Aggelis, D.G.; Van Hemelrijck, D.; Pyl, L. On the use of acoustic emission to identify the dominant stress/strain component in carbon/epoxy composite materials. Mech. Res. Commun. 2021, 111, 103663. [CrossRef]

7. Aggelis, D.G.; De Sutter, S.; Verbruggen, S.; Tsangouri, E.; Tysmans, T. Acoustic emission characterization of damage sources of lightweight hybrid concrete beams. Eng. Fract. Mech. 2019, 210, 181-188. [CrossRef]

8. Tsangouri, E.; Aggelis, D.G. A review of acoustic emission as indicator of reinforcement effectiveness in concrete and cementitious composites. Constr. Build. Mater. 2019, 224, 198-205. [CrossRef]

9. Chandarana, N.; Sanchez, D.M.; Soutis, C.; Gresil, M. Early damage detection in composites during fabrication and mechanical testing. Materials 2017, 10, 685. [CrossRef] [PubMed]

10. De Sutter, S.; Verbruggen, S.; Tysmans, T.; Aggelis, D.G. Fracture monitoring of lightweight composite-concrete beams. Compos. Struct. 2017, 167, 11-19. [CrossRef]

11. Abdelrahman, M.; ElBatanouny, M.; Dixon, K.; Serrato, M.; Ziehl, P. Remote monitoring and evaluation of damage at a decommissioned nuclear facility using acoustic emission. Appl. Sci. 2018, 8, 1663. [CrossRef]

12. Barat, V.A.; Terentyev, D.A.; Kostenko, P.P.; Bardakov, V.V.; Alyakritsky, A.L.; Koltsov, V.G.; Trofimov, P.N. Acoustic emission monitoring of industrial facilities under static and cyclic loading. Appl. Sci. 2018, 8, 1228.

13. Domaneschi, M.; Niccolini, G.; Lacidogna, G.; Cimellaro, G.P. Nondestructive monitoring techniques for crack detection and localization in RC elements. Appl. Sci. 2020, 10, 3248. [CrossRef]

14. Ono, K. Structural Health Monitoring of Large Structures Using Acoustic Emission-Case Histories. Appl. Sci. 2019, 9, 4602. [CrossRef]

15. Aggelis, D.G.; Shiotani, T.; Papacharalampopoulos, A.; Polyzos, D. The influence of propagation path on elastic waves as measured by acoustic emission parameters. Struct. Health Monit. 2012, 11, 359-366. [CrossRef]

16. Sause, M.G.R.; Hamstad, M.A. Numerical modeling of existing acoustic emission sensor absolute calibration approaches. Sens. Actuators A Phys. 2018, 269, 294-307. [CrossRef]

17. Scholey, J.J.; Wilcox, P.D.; Wisnom, M.R.; Friswell, M.I. Quantitative experimental measurements of matrix cracking and delamination using acoustic emission. Compos. Part A 2010, 41, 612-623. [CrossRef]

18. Aggelis, D.G.; Matikas, T.E. Effect of plate wave dispersion on the acoustic emission parameters in metals. Comput. Struct. 2012, 98, 17-22. [CrossRef]

19. Al-Jumaili, S.K.; Holford, K.M.; Eaton, M.J.; Pullin, R. Parameter correction technique (PCT): A novel method for acoustic emission characterisation in large-scale composites. Compos. Part B 2015, 75, 336-344. [CrossRef]

20. Hamstad, M.A.; Gallagher, A.O.; Gary, J. Effects of lateral plate dimensions on acoustic emission signals from dipole sources. J. Acoust. Emiss. 2001, 19, 258-274.

21. Gorman, M.R. Some connections between AE testing of large structures and small samples. Nondestruct. Test. Eval. 1998, 14, 89-104. [CrossRef]

22. Ospitia, N.; Aggelis, D.G.; Tsangouri, E. Dimension Effects on the Acoustic Behavior of TRC Plates. Materials 2020, $13,955$. [CrossRef] [PubMed]

23. Tsangouri, E.; Van Driessche, A.; Livitsanos, G.; Aggelis, D.G. Design, casting and fracture analysis of textile reinforced cementitious shells. Dev. Built Environ. 2020, 3, 100013. [CrossRef] 